\title{
What we look for in an article before accepting?
}

\author{
Varshil Mehta ${ }^{1 *}$ (iD) \\ ${ }^{1}$ Editor in Chief, Journal of Medical Research and Innovation. \\ *Corresponding Author's Mail: varshilmehta@gmail.com \\ *Cell: 9821112171
}

\section{Editorial}

People often say that pen is mightier than a sword. Truly, an article can either create a revolution, coin some words or may even prove a hypothesis as wrong. The Journal of Medical Research and Innovation (JMRI) was founded with same the fundamental thought and a view of revolutionizing the medical research at an affordable price or may be even for free for everyone.

With that said, we do not accept all articles. The acceptance rate $(66 \%$ in 2017 to approximately $55 \%$ in 2018) has fallen down and we are committed in reducing it further, not because we want to, but we have to! The main reasons for rejection are non-interesting article, repeated studies or cases, nothing new, plagiarism, many grammatical errors etc. I am going to discuss about the few main causes over here.

\section{Plagiarism}

The number one reason for a rejection of an article in JMRI, is plagiarism. Plagiarism is a disease which is yet pandemic today. Hence, we scan all articles as a first thing when we receive an article with the help of Plagiarism Checker X. Interestingly, every third or fourth article has some or the other plagiarized sentences. We may reject the paper or give a chance for the authors to correct it. We generally desk reject it, if the plagiarism content is found out to be more than $30 \%$.

\section{Old repeated research}

We often reject those papers which brings out nothing new. Though, we may accept few papers if they are published for the first time in a particular region (because the statistics may come out to be different with regards to different regions). However, many authors think that they may be able to publish papers in JMRI, as it is a new journal, but the reality smacks their hopes sooner than later. Out of 10 papers that we receive, at least 4 offer nothing new findings and we have to reject them.

\section{Language / Grammatical errors}

Many authors from non-English speaking countries face problems with writing. It is completely understandable as it is not theirs mother tongue and they yet know more languages than any-English speaking author. However, as the journal is being published in English, we cannot accept any article which have many grammatical errors. We have also begun Medkrux editing services for such authors who may find it difficult.

\section{Not following journals/COPE guidelines}

We have now made sure, that all articles should follow our own guidelines along with that of COPE's. This was just done so that we can improve our standards. 2019 will be a year where we shall be improving our standards to most international quality-based journals like BMJ, Lancet, American Journal of Medicine, etc.

\section{Who do not want an Open Peer Review}

Well JMRI is an open peer review journal which means that all the peer review processes that takes place shall be published alongside the article if accepted. This is JMRI's strength. There were few authors, who retracted their papers after submission as they realized that there shall be an open peer review for their articles.

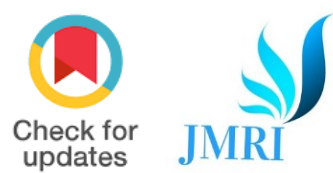

How to cite this article: Mehta V. What we look for in an article before accepting? Journal of Medical

Research and Innovation. 2019;3(2):e000170.

Doi:10.32892/jmri.170.

Publication history: Received:05-01-2019 Published: 05-01-2019

Copyright: Varshil Mehta. This is an open-access article distributed under the terms of the Creative Commons Attribution License CC-BY 4.0., which permits unrestricted use, distribution, and reproduction in any medium, provided the original author and sources are credited.

Conflict of Interest: NIL

MK Medkrux 
What we look for in an article before accepting?

Peer reviewer's suggestion to reject the paper

Well, there is no brainer. We reject the paper if the article has received negative comments or suggestion to reject the paper, even if the author is an editorial board member (we have already done that)!

Hopefully this paper shall help the prospective authors to understand the
Important points that we keep in mind before sending the paper for review or accepting it.

Regards,

Dr. Varshil Mehta

Editor in Chief

Journal of Medical Research and Innovation 